\begin{tabular}{|c|c|c|}
\hline 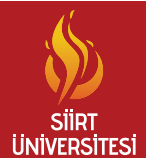 & $\begin{array}{c}\text { Türkiye Tarımsal Araştırmalar Dergisi } \\
\text { dergipark.org.tr/tutad }\end{array}$ & $\begin{array}{l}\text { Turk J Agric Res } \\
\text { 2020, 7(1): 85-95 } \\
\text { ○ TÜTAD } \\
\text { ISSN: 2148-2306 } \\
\text { e-ISSN: 2528-858X }\end{array}$ \\
\hline Bilimin Isuända & Araştırma Makalesi / Research Article & doi: 10.19159/tutad.671605 \\
\hline
\end{tabular}

\title{
Sorgum [Sorghum bicolor (L.) Moench] Genomunda BES1 Transkripsiyon Faktör Ailesinin Genom Çaplı Analizi*
}

\author{
Ayşe Gül KASAPOĞLU ${ }^{1}$, Emre İLHAN ${ }^{* * *}$, Damla KIZILKAYA ${ }^{2}$, \\ Arash HOSSEIN-POUR ${ }^{3}$, Kamil HALILOĞLU ${ }^{4}$ \\ ${ }^{\prime}$ Erzurum Teknik Üniversitesi, Fen Fakültesi, Moleküler Biyoloji ve Genetik Bölümü, Erzurum, TÜRKIYY \\ ${ }^{2}$ Ankara Yıldırım Beyazıt Üniversitesi, Geleneksel ve Tamamlayıcı Tıp Araştırma ve Uygulama Merkezi, Ankara, TÜRKIYYE \\ ${ }^{3}$ Erdabil Tarımsal ve Doğal Kaynaklar Araştırma ve Ĕ̆itim Merkezi, Moghan Tarla ve Bahçe Bilimleri Araştırma Bölümü, Erdabil, İRAN \\ ${ }^{4}$ Atatürk Üniversitesi, Ziraat Fakültesi, Tarla Bitkileri Bölümü, Erzurum, TÜRKİYE
}

Geliş Tarihi/Received: 07.01 .2020

Kabul Tarihi/Accepted: 24.02.2020

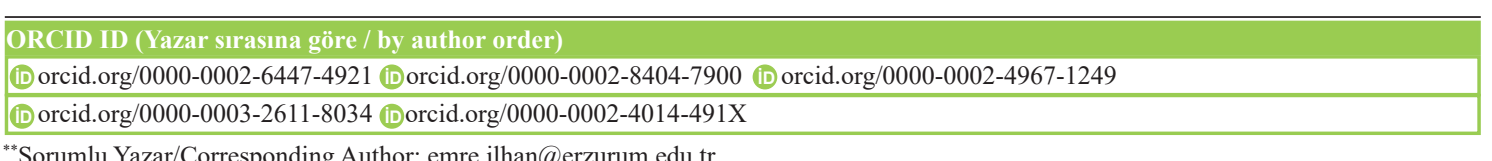

*Sorumlu Yazar/Corresponding Author: emre.ilhan@erzurum.edu.tr

Öz: BES1 transkripsiyon faktörü ailesi brassinosteroidlerin biyosentezinde önemli bir role sahiptir. Bitki büyüme ve gelişme süreçlerini ve çevresel streslere yanıt mekanizmasını etkileyen bir steroid hormonudur. Bu çalışmanın amacı sorgum [Sorghum bicolor (L.) Moench] bitkisinin farklı dokularında farklı azot kaynakları (kontrol gübresi, amonyak, nitrat, üre) uygulanarak bu dokulardaki BES1 transkripsiyon faktörünün ifade profillerini belirlemek ve in siliko olarak BES1 gen ailesinin üyelerini genom çapında tespit ederek karakterize etmektir. Sorgum genomunda amino asit sayıları 190 ile 716, moleküler ağırlıkları 35.27 ile $80.54 \mathrm{kDa}$ ve izoelektrik noktaları 5.0 ile 10.07 arasında değişen 9 Sobic-BES1 proteini belirlenmiştir. Gen yapısı analizlerinde tahmini ekzonların sayısı 2 ile 10 arasında değişmiştir. S. bicolor, Arabidopsis thaliana ve Oryza sativa türlerinin BES1 proteinleri kullanılarak filogenetik ilișki tespit edilmiștir. Evrimsel süreçte SobicBES1-4 ve Sobic-BES1-9 genlerinin segmental duplike olduğu belirlenmiştir. İn siliko gen ifade analizlerine göre farklı azot kaynaklarının ve su kontrolünün uygulandığı kök ve sürgün dokularında Sobic-BES1-4 ve -9 genlerinin ifade seviyelerinin en yüksek olduğu, diğer taraftan kullanılan azot kaynağına ve dokuya göre Sobic-BES1-1, Sobic-BES1-2 ve Sobic-BES1-8 genlerinin ifade seviyelerinin farklılık gösterdiği belirlenmiştir. Bu çalışmanın sonuçları fonksiyonel gen araştırmaları için bir temel sağlayacak olup, sorgum bitkisinde BES1 gen ailesinin anlaşılmasına katkı sunacaktır.

Anahtar Kelimeler: Biyoinformatik analizler, fitohormon, brassinosteroid, gen ailesi, gen ifadesi

\section{Genome-Wide Analysis of BES1 Transcription Factor Family in Sorghum [Sorghum bicolor (L.) Moench] Genome}

Abstract: The BES1 transcription factor family has an important role in the biosynthesis of brassinosteroids. It is a steroid hormone that affects plant growth and development processes and the mechanism of response to environmental stresses. The aim of this study was to determine the expression profiles of BES1 transcription factor in different tissues of sorghum [Sorghum bicolor (L.) Moench] by applying different nitrogen sources (controlled fertilized, ammonia, nitrate and urea) and to characterize BES1 gene family members through in silico methods. In sorghum genome, 9 Sobic-BES1 proteins with amino acid numbers ranged from 190 and 716, molecular weights between 35.27 and $80.54 \mathrm{kDa}$ and isoelectric points between 5.0 and 10.07 were determined. In gene structure analysis, the number of estimated exons ranged from 2 to 10. Phylogenetic relationship was determined using BES1 proteins of S. bicolor, Arabidopsis thaliana and Oryza sativa species. Sobic-BES1-4 and Sobic-BES1-9 genes were found to be segmental duplicated in the evolutionary process. According to the silico gene expression analysis, the expression levels of Sobic-BES1-4 and -9 genes were the highest in the root and shoot tissues where different nitrogen sources and irrigation control were applied. On the other hand, the expression levels of Sobic-BES1-1, Sobic-BES1-2 and Sobic-BES1-8 genes were differed according to the nitrogen source and tissue used. The

": Bu çalışma, 06-08 Kasım 2018 tarihlerinde Iğdır'da düzenlenen "I. International Iğdır Congress on Multidisciplinary Studies” kogresinde sözlü bildiri olarak sunulmuş olup, adı geçen kongre bildiriler kitabında özet metni yayınlanmıștır. 
results of this study will provide a basis for functional gene research and contribute to the understanding of the BES1 gene family in Sorghum bicolor.

Keywords: Bioinformatic analysis, phytohormone, brassinosteroids, gene family, gene expression

\section{Giriş}

C4 fotosentez yolunu kullanan sorgum [Sorghum bicolor (L.) Moench], marjinal alanlara yüksek adaptasyon göstermesi, azot kullanım etkinliğinin yüksek oluşu ve aşırı miktarda biyokütleye sahip olmasından dolayı dünyada en fazla ekimi yapılan önemli tahıl bitkisidir (Xu ve ark., 2018).

Sorgum germplazmı yüksek bir genetik çeşitliliğe sahiptir. Ayrıca büyüme özelliklerine ve kullanım amaçlarına bağlı olarak tane, yem bitkisi, enerji ve tatlı sorgum gibi sinıflara ayrılabilir (Xu ve ark., 2018). Birçoğu interfertil olan sorgum, hem kültür hem de yabani türleri içeren geniş bir cinstir (Menz ve ark., 2002). Taksonomik olarak, Sorghum bicolor (L.) Moench subps. bicolor'un 5 temel 1rk (bicolor, durra, caudatum, kafir ve guinea)'dan oluşan toplam 15 rkı vardır (Grenier ve ark., 2001). Sorgum genellikle kendi kendine tozlaşan bir bitki olup, önemli genetik ve morfolojik çeşitliliğe sahip olan bir diploiddir (Menz ve ark., 2002). Ayrıca kuraklığa olan tolerans1 sayesinde sorgum; tropik, subtropik ve sıcak bölgelerde yetiştirilen önemli bir tahıl bitkisidir (Smith ve Bhaskaran, 1986; Paterson ve ark., 2009).

Bitki büyümesi, çeşitli proteinleri şifreleyerek özelleşmiş genlerden oluşan bir ağ tarafından sistematik olarak kontrol edilmektedir. $\mathrm{Bu}$ proteinler arasında, spesifik nükleotid dizisine bağlanabilen transkripsiyon faktörleri, bitkilerin farklı gelişim aşamalarında önemli rol oynamaktadır (Glazebrook, 2001). BES1 [BRINSENSITIVE1(BRI1)-EMS-SUPPRESSOR1; B R-Duyarsız1-EMS-Baskilayıc11], Brassinosteroid lere (BR) yanıt veren genleri düzenleyen ve bu genlere bağlanan bitki spesifik transkripsiyon faktörlerinin yeni bir sınıfi olup, aynı zamanda bitkinin büyüme ve gelişimini düzenleyen bir steroid hormonudur (Clouse, 1996; Li ve Chory, 1999; Yin ve ark., 2005). Hücre uzaması ve hücresel büyüme, bazı BR-duyarlı BES1 hedef genlerine bağlıdır. Diğer taraftan BES1, konstitütif fotomorfogenez ve divarfizm (cücelik; CPD) ve DWARF4 (DWF4) gibi birkaç BR biyosentez enziminin ifadesini baskılamaktadır. Dahas1, BES1 sadece SAUR (küçük oskin artırıcı RNA, Small Auxin-Up RNA) benzeri proteinler ve IAA1 (indol 3-asetik asit uyarıc1, Indole-3-Acetic Acid Inducible) transkripsiyon faktörü gibi oksinlere yanıt veren genlerin yanında, oksinlerin uzamsal dağılımını kontrol eden ve oksinlerin hareketleri üzerine önemli etkileri olan oksin efektör yardımcılarını da (PIN4, PIN7) hedeflemektedir (Li, 2010). Ayrıca, bozulmuş BR üretimi veya algılaması olan bitkilerde, divarfizm, organ genişlemesinin azalması, apikali olma gibi birçok büyüme kusurları görülmektedir.

Diğer taraftan, bitkiler, yüksek ve düşük sicaklık stresi, kuraklık, tuzluluk, herbisit yaralanması, böcek ve patojen saldırısı da dahil olmak üzere bütün çevresel stres faktörlerinden brassinostreodiler tarafindan korunmaktadır (Khripach ve ark., 2000; Bajguz ve Hayat, 2009; Campos ve ark., 2009, Yang ve ark., 2011; Guo ve ark., 2013). BES1, BR sinyal yolunda önemli bir rol oynar. BES1, SAUR-AC-1 promotoründe var olan üç E kutu (CANNTG) dizisine bağlanmak için BIM1 (BES1-etkileşimli Myc-benzeri protein 1, BES1-interacting Myc-like protein 1), bHLH (temel sarmal-ilmek-sarmal, basic helix loop helix) domainiyle birlikte bir heterodimer oluşturan eşsiz bir DNA bağlanma domainidir (Fujioka ve Yokota, 2003; Yin ve ark., 2005). BES1 transkripsiyon faktörünün, diğer bHLH proteinlerinin temel bölgeleriyle oldukça benzer bir bölge içerdiği tahmin edilmektedir. bHLH proteinlerinin E kutusuna bağlanma spesifikliğini belirleyen Glu-13Arg-16 çifti BES1 ve BES1 aile üyelerinde korunmaktadır. Buna ek olarak, tüm bitkilerin bHLH proteinlerindeki oldukça yüksek ölçüde korunmuş iki lösin rezidüsü (Toledo-Ortiz ve ark., 2003) BES1 aile üyelerinde de mevcuttur (Yin ve ark., 2005). BES1 proteini, bir nükleer lokalizasyon sekansı (NLS), BES1 ve aile üyeleri arasında paylaşılan yüksek ölçüde korunmuş bir amino terminal domaini (N), bir BRASSINOSTEROID INSENSITIVE2 (BIN2), fosforilasyon domaini (P), bir PEST [prolin (P), glutamik asit (E), serin (S) ve treonin (T)'ce zengin bir protein dizisi] motifi (Li ve ark., 2012) ve bir karboksil terminal domaini (C) içermektedir. BES1'in merkezi $\mathrm{P}$ domaini, BIN2 (BRINSENSITIVE2-BR-Duyarsız2) kinazın hedefi olup BES1 proteininin yıkımını PEST motifi üstlenmektedir. $\mathrm{P}$ domaininin işlevi ise hala bilinmemektedir (Wang ve ark., 2002; Yin ve ark., 2005).

BES1 ve BZR1 (BR biyosentezini engelleyen brassinazol 1), brassinostreod sinyal yolağında iyi karakterize edilmiş iki transkripsiyon faktörü olup bitkilere özgüdürler. Ayrıca amino asit seviyesinde yüksek bir homolojiyi paylaşırlar (Wang ve ark., 
2002; Yin ve ark., 2002; Zhao ve ark., 2002). Her ikisi de $\mathrm{N}$ ucunda tipik bir bHLH DNA bağlama motifine sahiptir ve sirasıyla E-kutu (CANNTG) ve BRRE (CGTGT / CG) elemanlarını bağladığ1 gösterilmiştir (He ve ark., 2005; Yin ve ark., 2005).

Azot bitkisel üretimde eksikliğinin en fazla görüldüğü ayrıca en fazla ihtiyaç duyulan verim artırma özelliğine sahip bitki besin elementlerinden en önemli olanıdır (Kara, 2006). Azot, bazı durumlarda bitkilerde büyümeyi sınırlandırabilmesine rağmen, verimi arttırmak için kullanılan önemli bir elementtir (Öztürk ve ark., 2007). Yapılan araştırmalarda azot kaynağı olarak amonyum sülfat, amonyum nitrat, üre ve potasyum nitrat gibi birçok azotlu gübre formu kullanılmıştır (Timm ve Riekels, 1964; Lorenz ve ark., 1974; Singh ve ark., 1979; Bhol ve ark., 1989; Sharma, 1990; Anabousi ve ark., 1997).

$\mathrm{Bu}$ çalışmanın amacı, S. bicolor bitkisinin farklı dokularında farklı azot kaynakları (kontrol gübresi, amonyak, nitrat, üre) uygulanarak bu dokulardaki BES1 transkripsiyon faktörünün ifade profillerini belirlemek ve in siliko olarak BES1 gen ailesinin üyelerini genom çapında tespit ederek karakterize etmektir. Hem büyüme ve gelişmede hem de biyotik ve abiyotik stres koşullarına dayanıklılık sağlayan BES1 transkripsiyon faktörü gen ailesi üyeleri filogenetik ve yapısal düzeyde karakterize edilmiştir.

\section{Materyal ve Yöntem}

\subsection{BES1 transkripsiyon faktörlerinin belirlenmesi}

S. bicolor, Arabidopsis thaliana ve Oryza sativa genomlarındaki BES1 gen ailesinin protein, genomik, transkript ve CDS (kodlanan DNA dizileri) dizileri Pfam (protein ailesi) veri tabanından alınan Pfam Erişim Numarası (PF05687) kullanılarak Phytozome veritabanı v12.1.6 (Anonymous, 2019a)'dan elde edilmiştir. Sorgum, arabidopsis ve çeltik genomundaki bütün olası BES1 proteinlerini belirlemek için hem Phytozome veritabanının v12.1.6'daki blastp hem de HMM (gizli Markov model, Hidden Markov Model) (Anonymous, 2019b) aramas1 varsay1lan parametrelerle bu bitkilerin genomlarında taranmıştır. İlişkili olmayan diziler "decrease redundancy araci” (Anonymous, 2019c) kullanılarak elde edilmiştir. İlişkili dizilerdeki BES1 domaininin varlığı HMMER (Anonymous, 2019d) veritabanı kullanarak araştırılmıştır. Elde edilen BES1 proteinlerinin teorik izolektrik noktas1 (pI) ve moleküler ağırlığı "ProtParam aracı" (Anonmymous, 2019e) kullanılarak tespit edilmiştir.

\subsection{BES1 genlerinin yapısı, fiziksel yerleri, gen katlanmaları ve korunmuş motiflerin tespit edilmesi}

Sorgum, Arabidopsis ve çeltikteki BES1 proteinlerinin ekzon-intron bölgeleri hakkında bilgi edinmek için, Gene Structure Display Server v2.0 kullanılmıștır (Guo ve ark., 2007). Kodlanan DNA dizileri (CDS) ve genom dizileri kullanılarak Sobic-BES1 genlerinin bulunduğu yerlerinin bilgisi tahmin edilmiştir. Phytozome veritabanı v12.1.6 kullanılarak, Sobic-BES1 genlerinin kromozomal konumları ve boyutları belirlenmiştir.

Sobic-BES1 genleri tüm $S$. bicolor kromozomlarına işaretlenip MapChart programıyla çizilmiştir (Voorrips, 2002). Gen katlanma olayları "Bitki Genom Katlanma Veritabanı, BGKV" tarayıcısı (Anonymous, 2019f) kullanılarak tespit edilmiştir. Sobic-BES1 genlerinin ikili çiftleri arasındaki Non-sinonim oranları $(\mathrm{Ka})$, sinonim oranlar1 (Ks) ve evrimsel zorlamalar (Ka/Ks) PAL2NAL (Suyama ve ark., 2006) programı kullanılarak PAML arayüz aracında (Yang, 2007) hesaplanmıştır.

$\mathrm{Bu}$ bitkilerdeki BES1 proteinlerinin ilave korunmuş motiflerini tespit etmek için, "Multiple EM for Motif Elicition (MEME, Çoklu motif bulucu) Aracı" kullanılmıştır (Bailey ve ark., 2006). Minimum/maksimum genișlik ve motiflerin maksimum sayısı için sınırlar sırasıyla 6,50 ve 15 olarak ayarlanmıştır. Motif bölgeleri 2 ile 300 arasındadır. Bölge dağılımı tekrarların herhangi bir sayısı olarak ayarlanmıştır. Belirlenen motifler InterPro veritabanının varsayılan ayarlarında herhangi bir değişiklik yapmadan tarama yapılmıştır (Quevillon ve ark., 2005). Ayrıca sorgumda korunmuş bölge dizi analizleri için, bHLH ve BES1 domainlerinin dizi logo analizleri WEBLOGO online web aracından faydalanılarak çizilmiştir (Crooks ve ark., 2004).

\subsection{Filogenetik analizler ve dizi hizalama}

Filogenetik ve moleküler evrimsel analizler, MEGA v7 programı kullanılarak tespit edilmiş ve bu programla filogenetik ağaç temin edilmiştir (Tamura ve ark., 2011). Her bir dal için 1000 tekrarlı bootstrap değeri ile Neighbor-joining (NJ, Komşu katılım) metoduna göre yapılmıştır. Aynı soydan gelenlerin her biri için belirtilen sayılar, yüzde olarak ifade edilen bootstrap değerlerini temsil eder. Bu bitkilerdeki BES1 protein dizileri ClustalW kullanılarak hizalanmıştır (Thompson ve ark., 1997).

\subsection{Sinteni analizi}

$S$. bicolor ile $A$. thaliana ve $O$. sativa BES1 genlerinin ortologları BGKV'den (Anonymous, 
2019f) faydalanarak tespit edilmiştir (Lee ve ark., 2013). Sinteni haritas1 "iTAK-Plant Transcription Factor and Protein Kinase Identifier and ClassifierBitki transkripsiyon faktör ve protein kinaz belirleyici ve sinıflayıcı" tarayıcısı kullanılarak çizilmiştir (Zheng ve ark., 2016).

\section{5. İn siliko gen ifade analizi}

Illumina RNAseq veri setleri Phytozome veritabanı v12.1.6 kullanılarak elde edilmiştir. Dört farklı azot kaynağı (kontrol gübresi, amonyak, nitrat ve üre) ve su kontrolünün uygulandığı sorgumda kök ve sürgün doku kütüphanelerinde analiz edilmiştir. İn siliko ifade profilleri FPKM (Dizilenmiş her milyon baz çifti transkript dizisinin her kilobaz fragmanlarının beklenen say1sı) birimlerinde Cufflinks ile hesaplanmıştır (Trapnell ve ark., 2013). FPKM değerleri log2'ye dönüştürülerek CIMMiner (Anonymous, 2019g) algoritması ile heatmap elde edilmiştir.

\section{Bulgular ve Tartışma}

\subsection{Sorgum BES1 genlerinin kullanılması}

Tüm Sobic-BES1 genlerini belirlemek için Phytozome veritabanı v12.1.6'da bulunan sorgum, Arabidopsis ve çeltik genomlarında, Pfam veritabanından elde edilen Pfam erişim numarası (PF05687) kullanılarak anahtar kelime taramas1 (keysearch) yapılmıştır. Bu tarama sonucunda aynı genin alternatif transkript formları uzaklaştırılarak, BES1_N domainini taşıyan Sobic-BES1 genleri belirlenmiştir. Benzer protein homolojisine sahip sorgumda dokuz, Arabidopsis'te 8 ve çeltikte ise 6 gen tespit edilmiştir. HMMER veritabanı kullanılarak sorgum bitkisinde Glyco_hydro_14 domaini Sobic-BES1-2 ve Sobic-BES1-6 genlerinde belirlenmiştir. $\mathrm{Bu}$ çalışmaya benzer olarak GmBES1 genlerinde hem BES1_N hem de Glyco_hydro_14 domainleri tespit edilmiştir (Li ve ark., 2019). Sorgum genomundan elde edilen dokuz aday BES1 geni Tablo 1'de listelenmiştir. Sobic-BES1 genleri sorgumun 1, 2, 3, 4 ve 10 numaralı kromozomlarında dağılmıştır (Şekil 1).
En fazla gen kromozom 4 üzerinde Sobic-BES1-6, Sobic-BES1-7 ve Sobic-BES1-8 genleri bulunmuştur. Ayrıca bu genlerin teorik izoelektrik noktaları, moleküler ağırlıkları ve amino asit sayıları da verilmiştir. En yüksek amino asit sayısı 716 olup Sobic-BES1-6'ya aittir. En düşük amino asit say1s1 ise 190 amino aside sahip olan SobicBES1-5'e aittir. Ayrıca asidikten alkaliye değişen teorik izoelektrik noktası 5.00 ile 10.07 arasındadır. En yüksek değer Sobic-BES1-7'den elde edilen 10.07 iken, en düşük değer SobicBES1-2'den elde edilen 5.00 olmuştur. Moleküler ağırlık ise en düșük Sobic-BES1-5'te $20.99 \mathrm{kDa}$ olurken, en yüksek Sobic-BES1-6'da ise 80.53 kDa olmuştur. Daha önce yapılan çalışmalarda $A$. thaliana'da 8, Theobroma cacao'da 9, Carica papaya'da 6, çin lahanasında 15, Cucumis sativus'da 6, Vitis vinifera'da 6, Medicago truncatula'da 4 ve Oryza sativa'da 6 BES1 transkripsiyon faktörü tespit edilmiştir (Wu ve ark., 2016). BR sinyal yolunun önemli bir parçası olan BES1 genleri, çevresel baskılara karşı dayanıklılıkta bitkilere yardımcı olan birçok işlemde yer alır. Yu ve ark. (2008) BES1 trankripsiyon faktörlerinin bitki büyümesi, BR biyosentezi ve sinyallemesinde rol aldıklarını ispatlamışlardır. Wu ve ark. (2016) ise yaptıkları çalışmada 135 BES1 genini tanımlayıp analiz ettikten sonra BES1 genlerinin sadece kara bitkilerinde bulunduğunu ortaya koymuşlardır.

Tüm Genom Katlanmaları veya poliploidi doğada yaygın bilinen bir durumdur (Wendel, 2000; Kondrashov ve ark., 2002). Poliploididen elde edilen duplike genler adaptif evrim için önemli ham genetik materyaller sağlamaktadır (Flagel ve Wendel, 2009). Ka/Ks oran1 1'den büyükse gen dizisinin evrimi süresince pozitif seleksiyon olduğu, 1'den küçük olması arındırıcı seleksiyon ve 1'e eşit olması katlanma olaylarında doğal seleksiyon olduğunu belirtmektedir (Blanc ve Wolfe, 2004; Juretic ve ark., 2005; Cusack ve Wolfe, 2007). Gen katlanma analizleri sonucunda Sobic-BES1-4/Sobic-BES1-9 genlerinin segmental duplike genler olduğu görülmüştür. Segmental duplike genler Sobic-BES1-4/Sobic-BES1-9'un Ks

Tablo 1. Sorgum genomunda bulunan BES1 proteinleri hakkında bilgi*

\begin{tabular}{|c|c|c|c|c|c|}
\hline Gen ad1 & Phytozome adı & Kromozom lokasyonu & aa & MA (Da) & $\mathrm{pI}$ \\
\hline Sobic-BES1-1 & Sobic.001G511400 & Chr01:77886570-77891227 (-) & 412 & 41814.52 & 5.77 \\
\hline Sobic-BES1-2 & Sobic. $002 \mathrm{G} 136200$ & Chr02:20563849-20574672(+) & 596 & 67005.91 & 5.00 \\
\hline Sobic-BES1-3 & Sobic.002G353200 & Chr02:71635214-71637226 (-) & 336 & 35271.44 & 8.93 \\
\hline Sobic-BES1-4 & Sobic.003G026300 & Chr03:2228809-2231971 (+) & 348 & 36561.00 & 8.74 \\
\hline Sobic-BES1-5 & Sobic.003G046600 & Chr03:4267647-4268762(+) & 190 & 20992.17 & 9.18 \\
\hline Sobic-BES1-6 & Sobic.004G027800 & Chr04:2235985-2242049(+) & 716 & 80537.14 & 8.07 \\
\hline Sobic-BES1-7 & Sobic.004G102500 & Chr04:9584881-9586747 (-) & 399 & 40785.12 & 10.07 \\
\hline Sobic-BES1-8 & Sobic.004G102700 & Chr04:9632195-9633870 (-) & 375 & 38991.54 & 9.99 \\
\hline Sobic-BES1-9 & Sobic.010G163900 & Chr10:48237055-48240678 (+) & 356 & 37659.58 & 8.15 \\
\hline
\end{tabular}

${ }^{*}:(+)$ : Pozitif iplikçik, (-): Negatif iplikçik, aa: Amino asit sayısı, pI: Teorik izoeklektrik nokta, MA: Moleküler ağırlığı 


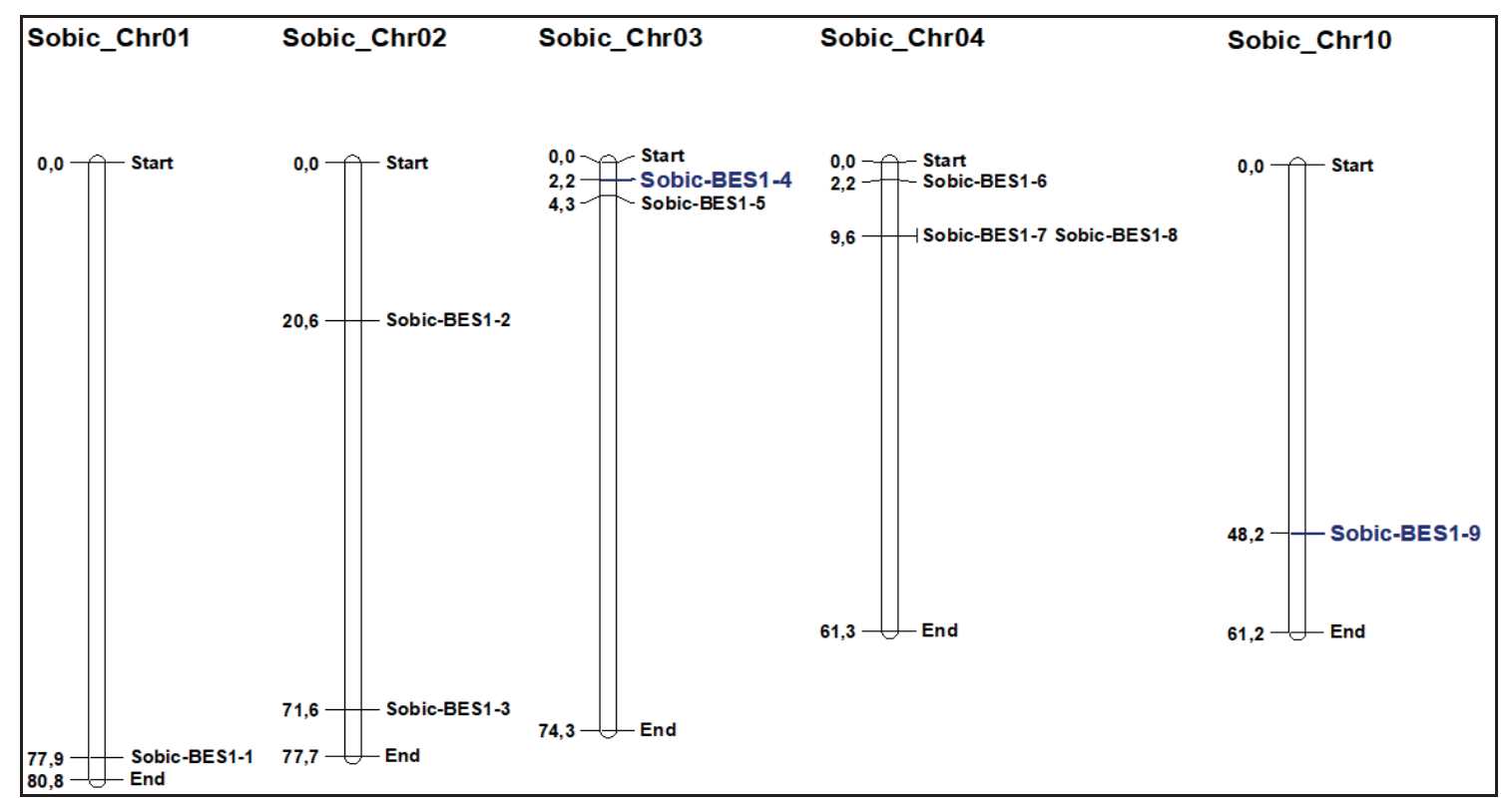

Şekil 1. Sobic-BES1 genlerinin sorgum kromozomundaki dağılımı*

*: Mavi renkle gösterilen genler segmental duplikasyonu belirtmektedir

değeri 13.177 ve Ka değeri 0.2382 olarak tespit edilmiştir. $\mathrm{Bu}$ genler arasındaki $\mathrm{Ka} / \mathrm{Ks}$ oranı 0.0180 olarak tespit edilmiştir. Bu sonuç sorgum bitkisinin evrimsel sürecinde yüksek düzeyde arındırıcı seleksiyon olduğunu göstermektedir.

\subsection{Sobic-BES1'lerin filogenetik analizi, korunmuş motifleri ve gen yapısı}

Sobic-BES1 proteinleri arasındaki ilișkiyi belirlemek için $S$. bicolor, A. thaliana ve $O$. sativa bitkilerinin BES1 genlerine ait protein dizileri kullanılarak filogenetik ağaç şekillendirilmiştir. Filogenetik ağaç BES1 proteinlerinin amino asit dizisine bağlı olarak 1000 tekrarlı bootstrap değeri ile komşu katılım metodu kullanılarak çizilmiştir (Şekil 2A). BES1 proteinleri I, II ve III olmak üzere 3 grupta toplanmıştır. I. grupta Sobic-BES11, Sobic-BES1-3, Sobic-BES1-4, Sobic-BES1-7, Sobic-BES1-8 ve Sobic-BES1-9 proteinleri, AT1G19350, AT1G78700, AT4G18890, AT1G75080, AT3G50750, AT4G36780, LOC Os01g10610, LOC Os06g35900, LOC_Os07g39220 ve LOC_Os02g13900 proteinleriyle; II. Grupta Sobic-BES1-2 ve SobicBES1-6 proteinleri AT5G45300, AT2G45880 ve LOC_Os02g03690 proteinleriyle; III. grupta ise Sobic-BES1-5 proteini LOC_Os01g08180 proteini ile ortoloji göstermiştir. Glycine max BES1 ve BES1 benzeri gen aileleri ile yapılan bir çalışmada çizilen filogenetik ağaçta iki grup elde edilmiştir (Li ve ark., 2019). Yine çin lahası ile yapılan çalışmada ise Arabidopsis, çeltik ve çin lahanasına ait BES1 gen ailesinin filogenetik ilişkileri tespit edilmiştir. $\mathrm{Bu}$ çalışmada 3 türün BES1 gen ailesi üç grupta toplanmıştır (Wu ve ark., 2016).
Aynı aileden gelen proteinler benzer motifleri paylaşmakta olup bunlar benzer fonksiyonlara da sahiptirler (Bailey ve ark., 2006). Şekil 2B'de MEME (v5.1.0) programı kullanılarak sorgum, Arabidopsis ve çeltik bitkilerindeki BES1 proteinlerinde yapılan korunmuş motif analizlerinde 15 korunmuş motif tespit edilmiştir. Belirlenen motiflerin uzunluğu 6-50 aminoasit aralığında olmuştur. Sorgumda en fazla motif Sobic-BES1-6' da (9 motif), en az motif ise SobicBES1-5 ve Sobic-BES1-8'de (2 motif) elde edilmiştir. Tüm Sobic-BES1 proteinlerinin Motif 1'i ve Sobic-BES1-5 hariç diğer tüm Sobic-BES1 genlerinin Motif 2'yi içerdiği tespit edilmiştir. Tablo 2'de motiflere karşılık gelen en iyi muhtemel eşleşme dizileri gösterilmiştir. Ayrıca Motif 1 ile yapılan InterPro analizleri sonucunda bu motifin BES1 domaini olduğu tespit edilmiştir.

Gen ailesi üyeleri arasında ekzon/intron çeşitlenmesi temelde 3 mekanizmayla çoklu gen ailelerinin evriminde önemli bir rol oynamaktadır. Bunlar ekzon/intron kazanımı veya kayb1, ekzonizasyon (intronik veya intergenik bir dizinin ekzonik hale geldiği bir süreç) /psödoekzonizasyon (ekzonizasyonun tersi bir süreç) ve insersiyon/delesyondur (Xu ve ark., 2012). Sorgum, Arabidopsis ve çeltik bitkilerinde ekzon ve intronların sayısı ve pozisyonu CDS ve BES1 geninden sorumlu genomik DNA dizilerinin karşılaştırılmasıyla belirlemiştir (Şekil 2C). Bu çalışmada BES1 genlerinin çoklu ekzon bölgeleri içerdiği bulunmuştur. BES1 genlerinin çoğunluğu aynı grupta hemen hemen benzer ekzon/intron yapılarını ve intron fazlarını paylaşmıştır. $\mathrm{Bu}$ analiz sonucunda Sobic-BES1 genleri arasında 


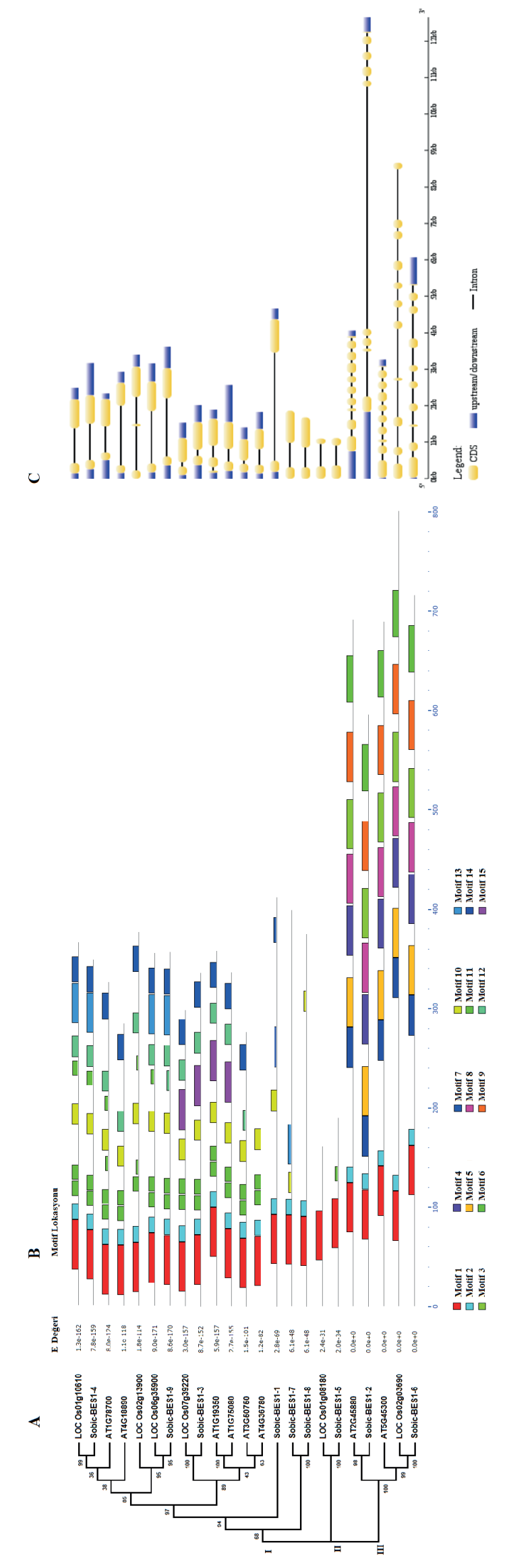

Şekil 2. (A) Sorgum, Arabidopsis ve çeltik bitkilerinin BES1 genleri arasındaki filogenetik ilişki, (B) MEME Suite programı kullanılarak BES1 proteinlerinde belirlenen korunmuş motifler. Benzer renkler aynı motifleri göstermektedir, (C) BES1 genlerinin gen yapıs1.

*: Mavi kutular 5-UTR ve 3-UTR, sarı kutular ekzon, siyah çizgi ise intron bölgelerini göstermektedir. 
Tablo 2. Sobic-BES1 genlerinde tahmin edilen motiflerin dizi bilgileri

\begin{tabular}{lclc}
\hline Motif no & Genişlik & En iyi muhtemel eşleşme & Domain \\
\hline Motif-1 & 50 & $\begin{array}{l}\text { ERENNKRRERRRRAIAAKIFAGLRAHGNYKLPKHCDNNEV } \\
\text { LKALCREAGW }\end{array}$ & $\begin{array}{c}\text { BES1/BZR1 bitki } \\
\text { transkripsiyon faktörü, } \\
\text { N-terminal }\end{array}$ \\
\hline Motif-2 & 16 & TVEPDGTTYRKGCKPP & N/A \\
\hline Motif-4 & 50 & $\begin{array}{l}\text { GHLFWARGPDNAGYYNSRPHETGFFCDGGDYDSYYGRFFL } \\
\text { NWYSQVLIDH }\end{array}$ & N/A \\
\hline Motif-5 & 50 & $\begin{array}{l}\text { NPDIFFTDREGRRNTECLSWGIDKERVLRGRTGIEVYFDFM } \\
\text { RSFRMEFDE }\end{array}$ & N/A \\
\hline Motif-6 & 15 & $\begin{array}{l}\text { NVDGVVVDCWWGIVEAWTPQKYEWSGYRDLFGIIREFKL } \\
\text { KVQVVMSFHES }\end{array}$ & N/A \\
\hline Motif-7 & 26 & NEFKFANGLVKPWEGERIHEECASDD & N/A \\
\hline Motif-8 & 50 & $\begin{array}{l}\text { EEGLISAIEIGLGASGELRYPSCPEKMGWKYPGIGEFQCYDR } \\
\text { YLQKSLRK }\end{array}$ & N/A \\
\hline Motif-9 & 50 & $\begin{array}{l}\text { VKIPSIYWWYRTASHAAELTAGFYNPSNRDGYSPVFRTLKK } \\
\text { HSVTLKFVC }\end{array}$ & N/A \\
\hline Motif-10 & 21 & LYPLGGSISAPVTPPLSSPTA & N/A \\
\hline Motif-11 & 47 & $\begin{array}{l}\text { WDHGLQIAVENALPCHDRDGYNKILDTAKPRNDPDRHHLS } \\
\text { FFAYRQL }\end{array}$ & N/A \\
\hline Motif-12 & 21 & FQIASTGPSSPTFSLVSPNPF & N/A \\
\hline Motif-13 & 40 & SRMCTPGQSGTCSPVIPGMPPHHDVQMVDGVPDDFAFGSS & N/A \\
\hline Motif-14 & 41 & DFTGTPYVPVYAMLPLGIINSHCQLVDPEGVRAELRHLKSL & N/A \\
\hline Motif-15 & 41 & KQSMDPFRHPFYAVSAPASPTRGRRFEHPDTIPECDESDVS & N/A \\
\hline
\end{tabular}

ekzon sayıları 2, 8 ve 9; intron sayıları ise bir, sekiz ve dokuz olmuştur. En yüksek ekzon sayısı Sobic-BES1-6' da 9 olarak belirlenirken, SobicBES1-1, -3, -4, -5, -7, -8 ve -9 genlerinde 2 ve Sobic-BES1-2 geninde ise 8 olarak belirlenmiştir.

Daha önce yapılan çalışmalarda BES1 transkripsiyon faktörünün bHLH domainiyle ilişkisi olduğu belirlenmiştir. Bu çalışmada ise WEBLOGO ara yüzü kullanılarak korunmuş bölge dizi analizi yapılmıştır. Bu analiz sonucunda Sobic-BES1 proteinleri içerisinde amino ucuna yakın bölgede temel sarmal ilmek sarmal domainleri ve protein dizileri tespit edilmiştir (Şekil 3).

\subsection{S. bicolor, A. thaliana ve $O$. sativa bitkilerindeki BES1 genlerinin karşılaştırmalı ve sinteni analizi}

$S$. bicolor, A. thaliana ve $O$. sativa bitkilerine ait BES1 proteinleri arasinda sinteni haritas1 çizilmiştir. Sinteni analizlerinde $S$. bicolor ve $O$. sativa bitkileri arasındaki sinteni ilişkisi tespit edilmiştir (Şekil 4). A. thaliana ve S. bicolor bitkileri arasinda yapılan sinteni analizinde ise BES1 transkripsiyon faktörü ailesi arasında bir ilişki tespit edilememiştir. $O$. sativa ile $S$. bicolor arasında yapılan sinteni analizi sonucunda SobicBES1-4, -7 ve -9 genleri ile LOC Os01g10610 ve LOC Os06g35900 genleriyle; Sobic-BES1-5 geni LOC_Os01g08180 geniyle; Sobic-BES1-5 ve -9 genleri LOC_Os02g13900 geniyle ve SobicBES1-3 geni LOC_Os07g39220 geni ile ortolog olduğu tespit edilmiştir.

\subsection{Sobic-BES1 genlerinin genom çaplı} ifadeleri

Dört farklı azot kaynağ 1 (kontrol gübresi, nitrat, üre ve amonyak) ve su kontrolü uygulanan sorgum bitkisinin sürgün ve kök dokusundan elde edilen özel doku kütüphanelerinde analiz edilmiştir (Şekil 5). Sürgün dokusunda gübre kontrolüyle kıyaslandığında nitrat ve amonyak kullanımı Sobic-BES1-1'in gen ifade seviyesini artırırken kontrolle karşılaştırıldığında üre kullanımı SobicBES1-1'in gen ifade seviyesini düşürmüştür. Sürgün dokusunda kontrollerle karşılaştırıldığında nitrat ve üre kullanımı Sobic-BES1-3'ün gen ifade düzeyini azaltmıştır. Kök dokularında ise farklı azot kaynağı uygulaması sonucunda Sobic-BES1-1 ve -3 'ün ifade seviyesinde önemli bir değişiklik tespit edilmemiştir. Kök dokusunda üre ve nitrat uygulamas1 Sobic-BES1-6'nın gen ifadesini azaltmıştır. Kök dokularında üre ve amonyak kullanımı Sobic-BES1-8'in gen ifade seviyesini düşürmüştür. Farklı azot kaynağı kullanımı sürgün dokularında Sobic-BES1-6 ve -8 genlerinde herhangi bir ifade değişikliği meydana getirmemiştir. Farklı azot kaynağı kullanılması hem kök hem de sürgün dokularında Sobic-BES1$4,-5,-7$ ve -9 genlerinin ifade seviyesini değiştirmemiştir. Farklı azot kaynaklarının (kontrol, amonyak, nitrat, üre ve gübre) uygulandığ 1 bitkinin hem kök ve hem de sürgün dokularında kontrole göre en yüksek ifade gösteren gen Sobic-BES1-4 ve -9 iken kök dokularında en düşük ifade gösteren gen Sobic-BES1-8 ve sürgün dokularında ise en düşük ifade gösteren gen Sobic- 


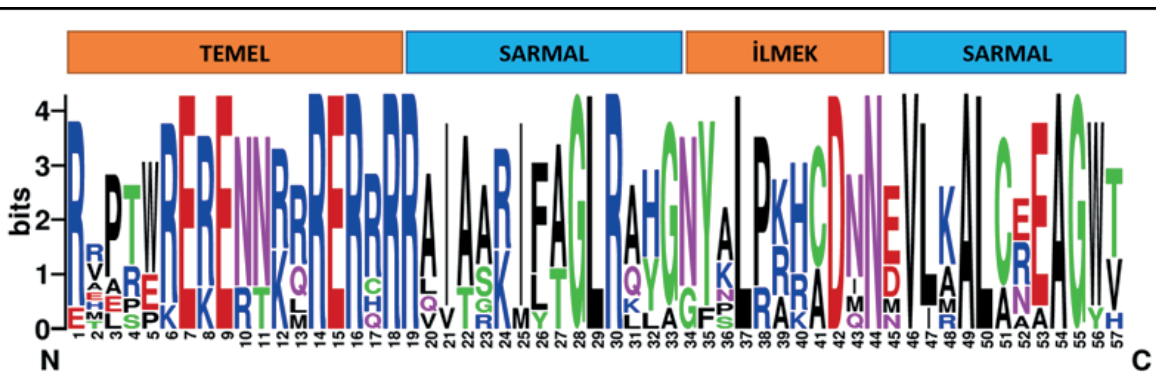

Sobic-BES1-1 RVPTWRERENNRRRERRRRAIASKIFTGLRAHGNYALRRHCDNNEVLKALCEEAGWT Sobic-BES1-2 RRARE-EKERTKMRERQRRAITGRILAGLRQHGNYSLRARADINEVIAALAREAGWV Sobic-BES1-3 RTPTWKERENNKRRERRRRAIAAKIFTGLRALGNYKLPKHCDNNEVLKALCREAGWV Sobic-BES1-4 RMPTWRERENNKRRERRRRAIAAKIFAGLRAHGGYKLPKHCDNNEVLKALCNEAGWV Sobic-BES1-5 RHPTPRERENNRQRERRRRQVAARIYAGLRAHAGYALPKHADQNDVLRALCAEAGYH Sobic-BES1-6 EREREREKERTKLRERHRRAITSRMLAGLRQHGNFPLPARADMNDVLAALARAAGWT Sobic-BES1-7 RAPSWRERENNRQRERCRRVIARRIFAGLRLYGNYALPRHCDNNNVLMALCEEAGWT Sobic-BES1-8 RELPWRERENNRRRERRRRLIAARIFTGLRKYGNYALPRKCDNNMVLKALCEEAGWT Sobic-BES1-9 RVPTWRERENNRRRERRRRAIAAKIFAGLRAYGNYNLPKHCDNNEVLKALCNEAGWT

Şekil 3. Sobic-BES1 gen ailesindeki korunmuş bHLH domainleri ve protein dizileri

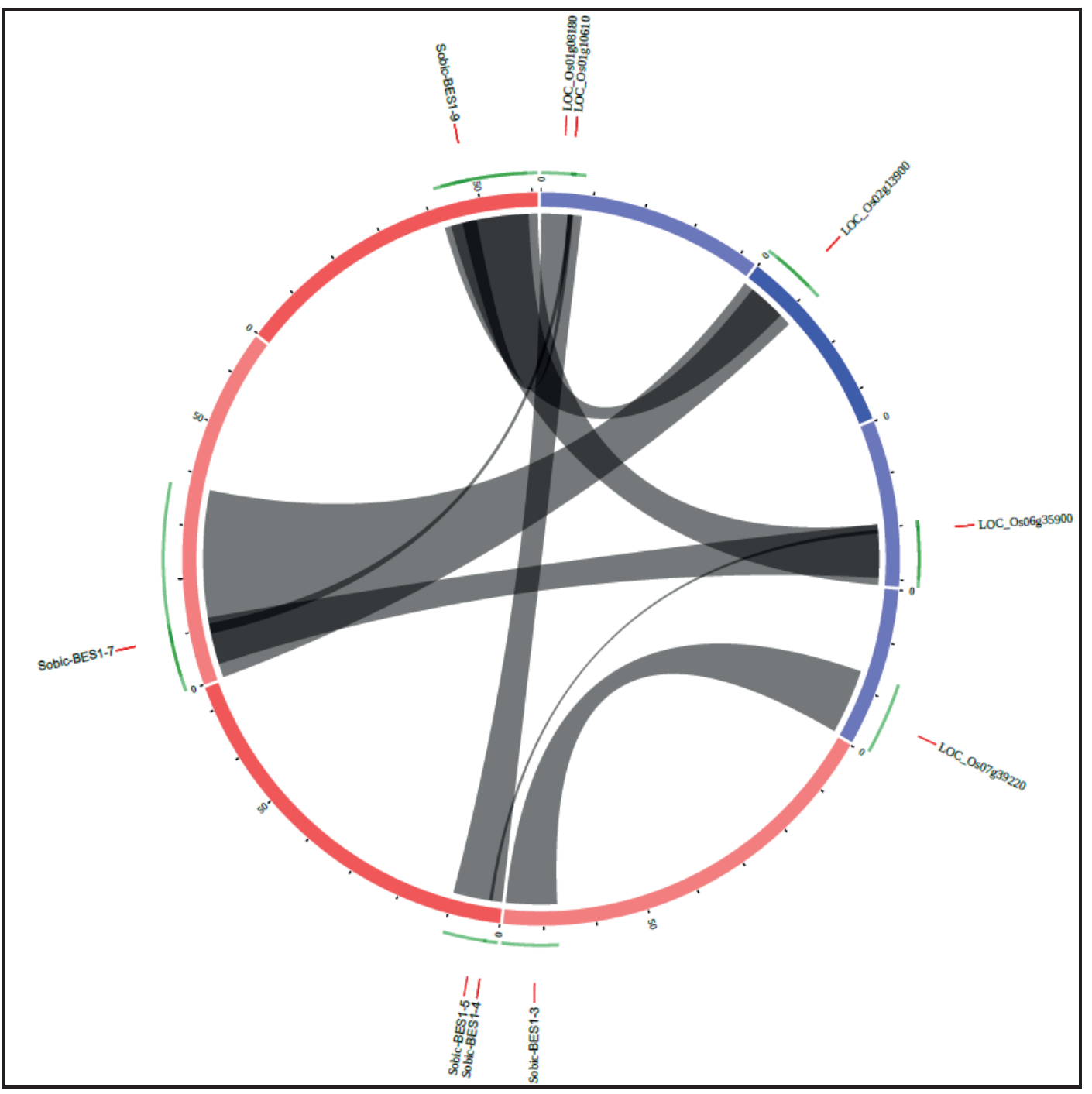

Şekil 4. Sobic-BES1 genlerinin genom çaplı sinteni analizi. S. bicolor ve O. sativa arasındaki karşılaştırmalı harita 


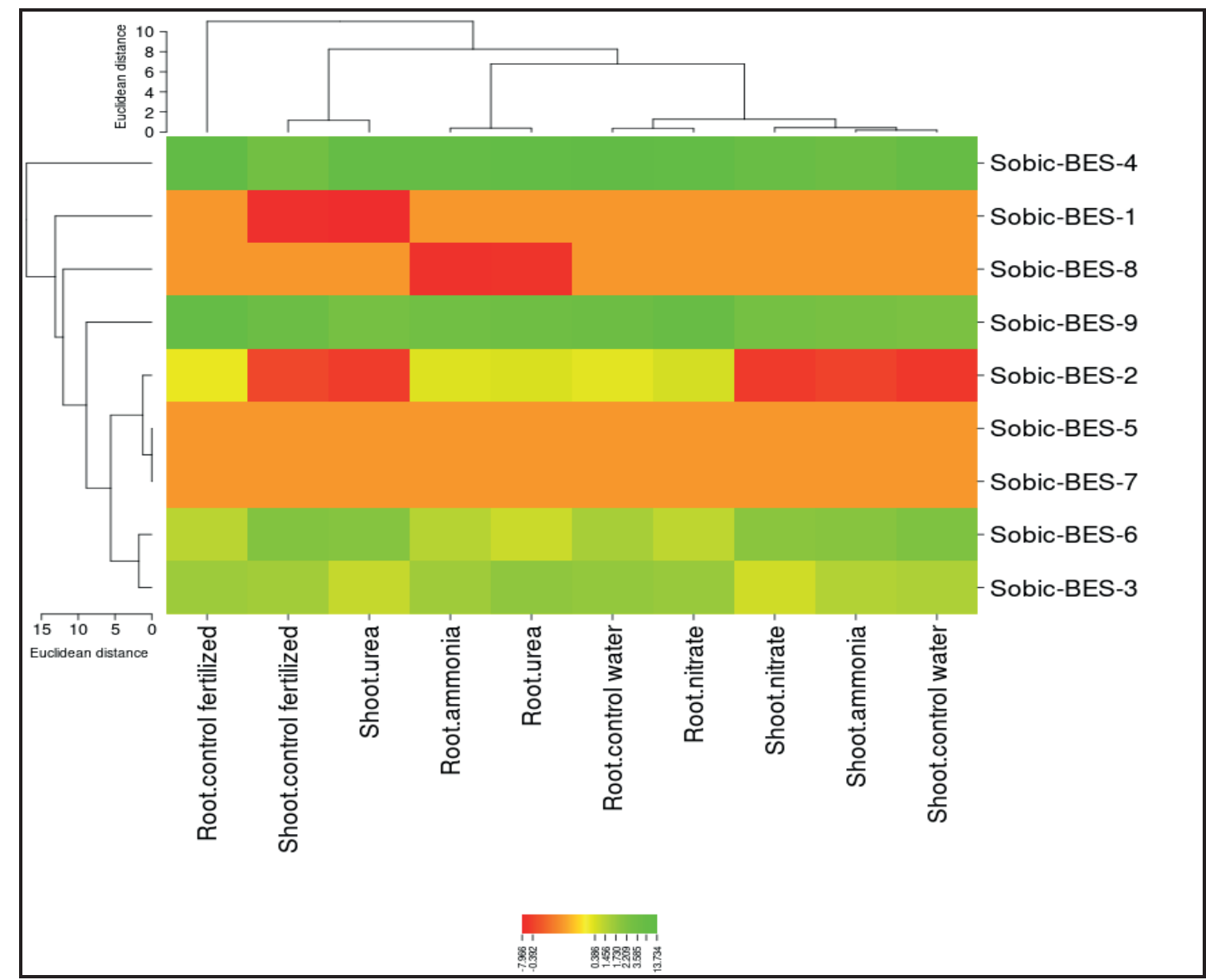

Şekil 5. Sorgum bitkisinin farklı azot kaynaklarının uygulandığı kök ve sürgün dokularında yapılan ifade analizi (Heatmap)

BES1-2 olarak belirlenmiștir. Bu çalıșmadan elde edilen verilere göre Sorghum bicolor bitkisinde genel olarak su ve gübre kontrolleriyle karşılaştırıldığında nitrat, üre ve amonyak uygulamaların bitkinin kök ve sürgün dokularındaki genellikle BES1 transkripsiyon faktörlerinin ifade düzeylerinin azalmasına neden olduğu tespit edilmiştir.

\section{Sonuçlar}

Sorgum genomunda bulunan BES1 gen ailesi ile in siliko olarak yapılan bu çalışmada 9 Sobic-BES1 üyesi tespit edilmiştir. Bulunan genler dört farklı sorgum kromozomunda dağılım göstermiştir. Sorgum bitkisinin 4 farklı azot kaynağının uygulandığı kök ve sürgün dokularında in siliko olarak gerçekleştirilen gen ifadesi analizlerinde ise Sobic-BES1 genlerinin ifade farklılıkları belirlenmiştir. Sobic-BES1 genlerinin ifade profilleri bu genlerin farklı azot kaynaklarına karş1 farklı dokularda değişken oranlarda ifade olduğunu ortaya çıkarmıştır. Bu çalışmanın sonuçları gelecekte sorgum bitkisi ile yapilacak olan islah ve verim çalışmalarında kullanılabilecektir.

\section{Kaynaklar}

Anabousi, O.A.N., Hattar, B.J., Suwwan, M.A., 1997. Effect of rate and source of nitrogen on growth, yield and quality of potato (Solanum tuberosum) under jordon valley conditions. Agricultural Sciences, 24(2): 242-259.

Anonymous, 2019a. Phytozome Database. (https:// phytozome.jgi.doe.gov/pz/portal.html), (Erişim tarihi: 18.09.2019).

Anonymous, 2019b. Hidden Markov Model (HMM). (http://www.ebi.ac.uk), (Erişim tarihi: 18.09.2019).

Anonymous, 2019c. Decrease Redundancy Tool. (http:// web.expasy.org/decrease redundancy/), (Erișim tarihi: 18.09.2019).

Anonymous, 2019d. HMMER. (http://www.ebi.ac.uk), (Erişim tarihi: 18.09.2019).

Anonymous, 2019e. ProtParam. (http://web. expasy.org/protparam), (Erişim tarihi: 18.09.2019).

Anonymous, 2019f. Plant Genome Duplication Database. (http://chibba.agtec.uga.edu/duplication/ index/locus), (Erişim Tarihi: 25.09.2019).

Anonymous, 2019g. CIMMiner. (https://discover. nci.nih.gov/cimminer/), (Erişim tarihi: 02.10.2019).

Bailey, T.L., Williams, N., Misleh, C., Li, W.W., 2006. MEME: Discovering and analyzing DNA and 
protein sequence motifs. Nucleic Acids Research, 34: W369-W373.

Bajguz A., Hayat S., 2009. Effects of brassinosteroids on the plant responses to environmental stresses. Plant Physiol Biochem, 47(1): 1-8.

Bhol, B.B., Rao G., Lenka, D.D., 1989. Relative efficiency of sources of nitrogen on the yield of potato. Indian Journal of Agronomy, 34(1): 132-133.

Blanc, G., Wolfe, K.H., 2004. Functional divergence of duplicated genes formed by polyploidy during Arabidopsis evolution. The Plant Cell, 16(7): 16791691.

Campos, M.L., De Almeida, M., Rossi, M.L., Martinelli, A.P., Litholdo Junior, C.G., Figueira, A., Pereira, Peres, L.E., 2009. Brassinosteroids interact negatively with jasmonates in the formation of antiherbivory traits in tomato. Journal of Experimental Botany, 60(15): 4347-4361.

Clouse, S.D., 1996. Molecular genetic studies confirm the role of brassinosteroids in plant growth and development. Plant Journal, 10(1): 1-8.

Crooks, G.E., Hon, G., Chandonia, J.M., Brenner, S.E., 2004. WebLogo: A sequence logo generator. Genome Research, 14(6): 1188-1190.

Cusack, B.P., Wolfe, K.H., 2007. When gene marriages don't work out: divorce by subfunctionalization. Trends in Genetics, 23(6): 270-272.

Flagel, L.E., Wendel, J.F., 2009. Gene duplication and evolutionary novelty in plants. New Phytologist, 183(3): 557-564.

Fujioka, S., Yokota, T., 2003. Biosynthesis and metabolism of brassinosteroids. Annual Review of Plant Biology, 54(1): 137-164.

Glazebrook, J., 2001. Genes controlling expression of defense responses in Arabidopsis-2001 status. Current Opinion Plant Biology, 4(4): 301-308.

Grenier, C., Bramel-Cox, P.J., Hamon, P., 2001. Core collection of sorghum: I. Stratification based on ecogeographical data. Crop Science, 41(1): 234-240.

Guo, A., Zhu, Q., Chen, X., Luo, J., 2007. GSDS: a gene structure display server. Yi Chuan $=$ Hereditas, 29(8): 1023-1026.

Guo, R., Qian, H., Shen, W., Liu, L., Zhang, M., Cai, C., Zhao, Y., Qiao, J., Wang, Q., 2013. BZR1 and BES1 participate in regulation of glucosinolate biosynthesis by brassinosteroids in Arabidopsis. Journal of Experimental Botany, 64(8): 2401-2412.

He, J.X., Gendron, J.M., Sun, Y., Gampala, S.S., Gendron, N., Sun, C.Q., Wang, Z.Y., 2005. BZR1 is a transcriptional repressor with dual roles in brassinosteroid homeostasis and growth responses. Science, 307(5715): 1634-1638.

Juretic, N., Hoen, D.R., Huynh, M.L., Harrison, P.M., Bureau, T.E., 2005. The evolutionary fate of MULEmediated duplications of host gene fragments in rice. Genome Research, 15(9): 1292-1297.

Kara, B., 2006. Çukurova koşullarında değişik bitki sıklıkları ve farklı azot dozlarında değişik bitki sıklıkları ve farklı azot dozlarında mısırın verim ve verim özellikleri ile azot alım ve kullanım etkinliğinin belirlenmesi. Doktora tezi, Çukurova Üniversitesi Fen Bilimleri Enstitüsü, Adana.

Khripach, V., Zhabinskii, V., de Groot, A., 2000. Twenty years of brassinosteroids: steroidal plant hormones warrant better crops for the XXI century. Annals Botany, 86(3): 441-447.

Kondrashov, F.A., Rogozin, I.B., Wolf, Y.I., Koonin, E.V., 2002. Selection in the evolution of gene duplications. Genome biology, 3(2002): research0008-1.

Lee, T.H., Tang, H.B., Wang, X.Y., Paterson, A.H., 2013. PGDD: A database of gene and genome duplication in plants. Nucleic Acids Research, 41(D1): D1152-D1158.

Li, B., Hu, Q., Xu, R., Ren, H., Fei, E., Chen, D., Wang, G., 2012. Hax-1 is rapidly degraded by the proteasome dependent on its PEST sequence. $B M C$ Cell Biology, 13(1): 1-10.

Li, J., Chory, J., 1999. Brassinosteroid actions in plants. Journal of Experimental Botany, 50(332): 275-282.

Li, L., 2010. The mechanism and network of BES1 mediated transcriptional regulation in Brassinosteroids (BR) pathway in Arabidopsis. Graduate Theses and Dissertations, pp. 11326.

Li, Q., Guo, L., Wang, H., Zhang, Y., Fan, C., Shen, Y., 2019. In silico genome-wide identification and comprehensive characterization of the BES1 gene family in soybean. Heliyon, 5(6): e01868.

Lorenz, O.A., Weir, B.L., Bishop, J.C., 1974. Effect of sources of nitrogen on yield and nitrogen absorption of potatoes. American Potato Journal, 51(2): 56-65.

Menz, M.A., Klein, R.R., Mullet, J.E., Obert, J.A., Unruh, N.C., Klein, P.E., 2002. A high-density genetic map of Sorghum bicolor (L.) Moench based on 2926 AFLP ${ }$, RFLP and SSR markers. Plant molecular biology, 48(5-6): 483-499.

Paterson, A.H., Bowers, J.E., Bruggmann, R., Dubchak, I., Grimwood, J., Gundlach, H., Haberer, G., Hellsten, U., Mitros, T., Poliakov, A., 2009. The Sorghum bicolor genome and the diversification of grasses. Nature, 457(7229): 551-556.

Öztürk, E., Kara, K., Polat, T., 2007. Azotlu gübre formları ve uygulama zamanlarının patatesin verimi ile yumru büyüklüğü üzerine etkisi. Tekirdăg Ziraat Fakültesi Dergisi, 4(2): 127-135.

Quevillon, E., Silventoinen, V., Pillai, S., Harte, N., Mulder, N., Apweiler, R., Lopez, R., 2005. InterProScan: Protein domains identifier. Nucleic Acids Research, 33(Suppl_2): W116-W120.

Sharma, U.C., 1990. Effect of sources and methods of nitrogen application on yield and nitrogen uptake of potato (Solanum tuberosum) in Meghalaya. Indian Journal of Agricultural Sciences, 60(2): 119-122.

Singh, D., Singh, M., Sandhu, H.S., 1979. Effects of different nitrogen sources and of biuret in urea on the growth and yield of potato and its nutrient uptake. Indian Journal of Agricultural Sciences, 49: 641-648.

Smith, R.H., Bhaskaran, S., 1986. Sorghum [Sorghum bicolor (L.) Moench]. Crops I, pp: 220-233. 
Suyama, M., Torrents, D., Bork, P., 2006. PAL2NAL: robust conversion of protein sequence alignments into the corresponding codon alignments. Nucleic Acids Research, 34: W609-W612.

Tamura, K., Peterson, D., Peterson, N., Stecher, G., Nei, M., Kumar, S., 2011. MEGA5: Molecular evolutionary genetics analysis using maximum likelihood, evolutionary distance, and maximum parsimony methods. Molecular Biology and Evolution, 28(10): 2731-2739.

Thompson, J.D., Gibson, T.J., Plewniak, F., Jeanmougin, F., Higgins, D.G., 1997. The CLUSTAL X windows interface: flexible strategies for multiple sequence alignment aided by quality analysis tools. Nucleic Acids Research, 25(24): 4876-4882.

Timm, H., Riekels, J.W., 1964. Growth, yield, and composition of onion, barley, and potato plants as affected by phosphorus and ammoniacal nitrogen fertilization. Agronomy Journal, 56(3): 335-340.

Toledo-Ortiz, G., Huq, E., Quail, P.H., 2003. The Arabidopsis basic/helix-loop-helix transcription factor family. Plant Cell, 15(8): 1749-1770.

Trapnell, C., Roberts, A., Goffl, O., Pertea, G., Kim, D., Kelley, D.R., Pimentel, H., Salzberg, S.L., Rinn, J.L., Pachter, L., 2013. Differential gene and transcript expression analysis of RNAseq experiments with TopHat and Cufflinks. Nature Protocols, 7(3): 562-578.

Voorrips, R.E., 2002. MapChart: Software for the graphical presentation of linkage maps and QTLs. Journal of Heredity, 93(1): 77-78.

Wang, Z.Y., Nakano, T., Gendron, J., He, J., Chen, M., Vafeados, D., Chory, J., 2002. Nuclear-localized BZR1 mediates brassinosteroid-induced growth and feedback suppression of brassinosteroid biosynthesis. Developmental Cell, 2(4): 505-513.

Wendel, J.F., 2000. Genome evolution in polyploids. In Plant Molecular Evolution, 42: 225-249.

Wu, P., Song, X., Wang, Z., Duan, W., Hu, R., Wang, W., Hou, X., 2016. Genome-wide analysis of the BES1 transcription factor family in Chinese cabbage
(Brassica rapa ssp. pekinensis). Plant Growth Regulation, 80(3): 291-301.

Xu, G., Guo, C., Shan, H., Kong, H., 2012. Divergence of duplicate genes in exon-intron structure. Proceedings of the National Academy of Sciences, 109(4): 1187-1192.

Xu, H., Ding, A., Chen, S., Marowa, P., Wang, D., Chen, M., Zhou, G., 2018. Genome-wide analysis of sorghum GT47 family reveals functional divergences of MUR3-like genes. Frontiers in Plant Science, 9: 1773.

Yang, D.H., Hettenhausen, C., Baldwin, I.T., Wu, J., 2011. BAK1 regulates the accumulation of jasmonic acid and the levels of trypsin proteinase inhibitors in Nicotiana attenuata's responses to herbivory. Journal of Experimental Botany, 62(2): 641-652.

Yang, Z.H., 2007. PAML 4: Phylogenetic analysis by maximum likelihood. Molecular Biology and Evolution, 24(8): 1586-1591.

Yin, Y., Vafeados, D., Tao, Y., Yoshida, S., Asami, T., Chory, J., 2005. A new class of transcription factors mediates brassinosteroid-regulated gene expression in Arabidopsis. Cell, 120(2): 249-259.

Yin, Y., Wang, Z.Y., Mora-Garcia, S., Li, J., Yoshida, S., Asami, T., Chory, J., 2002. BES1 accumulates in the nucleus in response to brassinosteroids to regulate gene expression and promote stem elongation. Cell, 109(2): 181-191.

Yu, X., Li, L., Li, L., Guo, M., Chory, J., Yin, Y., 2008. Modulation of brassinosteroid-regulated gene expression by Jumonji domain-containing proteins ELF6 and REF6 in Arabidopsis. Proceedings of the National Academy of Sciences, 105(21): 7618-7623.

Zhao, J., Peng, P., Schmitz, R.J., Decker, A.D., Tax, F.E., Li, J., 2002. Two putative BIN2 substrates are nuclear components of brassinosteroid signaling. Plant Physiology, 130(3): 1221-1229.

Zheng, Y., Jiao, C., Sun, H., Rosli, H. G., Pombo, M. A., Zhang, P., Zhao, P.X., 2016. iTAK: a program for genome-wide prediction and classification of plant transcription factors, transcriptional regulators, and protein kinases. Molecular Plant, 9(12): 16671670 . 